SALUD PÚBLICA Y ADMINISTRACIÓN SANITARIA

Las vacunaciones antivariólicas en Navarra (España) entre septiembre y noviembre de 1801

\title{
Smallpox vaccinations in Navarre (Spain) between September and November 1801
}

\section{J.J. Viñes}

\section{RESUMEN}

Se da noticia de la localización en el Archivo de D. Gaspar Castellano de Gastón, del documento que atestigua las primeras inoculaciones con linfa vacunal en Errazu, localidad del Valle de Baztán (Navarra), realizadas el 2 de Noviembre de 1801, por el médico de San Juan de Pie de Puerto (Francia) Dr. Iribarren Ayzin, desde el brazo de una muchacha francesa de 18 años, conducida personalmente por él, a instancia de D. Josef Juaquín Gastón Alcalde del Valle del Baztán.

El nuevo hallazgo sirve de homenaje 200 años después a la primera expedición de Salud Pública entre 1803 y 1806, dirigida por el médico alicantino D. Francisco Xavier Balmis, dando la vuelta al mundo, con el fin de difundir la vacuna entre todas las razas y zonas del mundo conocidas.

Palabras clave. Vacunación. Viruela.

\begin{abstract}
We communicate the discovery in the Archive of D. Gaspar Castellano de Gastón of a document providing evidence of the first inoculations with lymph vaccine in Errazu, a village in the Baztán Valley (Navarre). These were carried out on November $2^{\text {nd }}$ 1801, by a doctor from San Juan Pie de Puerto (France), Dr. Iribarren Ayzin, from the arm of a French girl aged 18 , personally brought by him at the request of D. Josef Juaquín Gastón, Mayor of the Baztán Valley.

The new finding serves as homage, 200 hundred years later, to the first Public Health expedition, carried out between 1803 and 1806, which travelled around the world in order to spread the vaccine amongst all the races and areas of the known world. The expedition was led by D. Francisco Xavier Balmis, a doctor from Alicante.
\end{abstract}

Key words. Vaccine. Smallpox.

An. Sist. Sanit. Navar. 2004; 27 (3): 359-371.

Profesor Titular de Medicina Preventiva y Salud Pública. Universidad Publica de Navarra. Pamplona.

Aceptado para su publicación el 5 de octubre 2004.

\section{Correspondencia:}

José Javier Viñes

Pabellón de Docencia

Recinto Hospital de Navarra

Irunlarrea, 3

31008 Pamplona 


\section{INTRODUCCIÓN}

A través de Don Gaspar Castellano de Gastón tuve conocimiento de que había localizado entre la documentación de los archivos de la familia Gastón de Iriarte, de los que es depositario como descendiente directo, de una descripción de la vacunación de la viruela en la localidad de Errazu cuando su antepasado D. José Joaquín Gastón de Iriarte era alcalde, juez capitán a guerra trienal del Noble Valle y Universidad del Baztán, entre mayo de 1799 y mayo de 1802 como consta en su nombramiento en el Archivo familiar (Fig. 1 y 2). El documento que me facilitó es del tamaño de un folio doblado en cuarto, manuscrito con 45 líneas que ocupa dos de sus caras y un tercio de la tercera cara. (Fig. 3)

Se trata de un relato del acontecimiento de la vacunación, que no se encuentra firmado ni fechado, queriendo dejar constancia su redactor de un hecho estimado como trascendente, que se inicia con el signo de la Cruz y con un solemne encabezamiento: "Valle de Baztán en el Reyno de Navarra".

La redacción y caligrafía corresponden al siglo XIX, realizada por persona cultivada en la escritura (puede compararse con las redacciones de la Gazeta de Madrid de la misma época) con pulso firme y que corresponde a algún protagonista o testigo directo de todos los hechos relatados, cuidando la descripción no sólo del hecho social de la vacunación, sino también de los aspectos científicos y de la comprobación empírica y experimental del resultado, por lo que puede imputarse su redacción a persona ilustrada, de entre las personas que introdujeron la vacunación en el Valle del Baztán. Desconocemos si anteriormente se hubiera practicado la variolización o inoculación del virus viruela natural, práctica extendida en Europa desde 1721 con algunos éxitos y muchos fracasos y accidentes mortales.

La autenticidad del documento está acreditada, ya que su tenedor es descen- diente en línea directa del que fuera alcalde de Errazu el citado José Joaquín Gastón que fue padre del tatarabuelo del actual propietario de la documentación familiar. La familia Gastón de Iriarte son originarios de la localidad de Errazu de la casa Iriartea ${ }^{1}$, conocida también como casa La Aduana por haber sido en ella instalado este órgano del Estado a final del siglo XIX. Una hermana de José Joaquin fue a casar con un indiano a Irurita (Valle del Baztán) por lo que su padre D. Pedro José Gastón levantó otra casa solar similar, donde más tarde se unieron ambas ramas hasta la actualidad. Del citado linaje de hidalguía* descienden personalidades ilustres, entre ellos D. Miguel Gastón de Iriarte, que fue Teniente General de la Real Armada² en 1769.

D. José Joaquín Gastón de Iriarte nació en casa Iriartea en Errazu en el valle de Baztán. Su nieto José María Gastón Echeverz, nació en Maya/Amaiur en 1819; abogado y de actividad social relevante en asuntos de Navarra se alineó en la causa liberal, siendo Diputado en Cortes Españolas, Diputado Foral y Gobernador Civil de Navarra. Su hijo Joaquín María Gastón Elizondo, nacido en Irurita (Valle de Baztán) también abogado y político liberal desempeñó los cargos de Diputado a Cortes y Diputado $\mathrm{Foral}^{3}$. Tuvo un hijo varón y tres hijas; una de ellas la mayor María Asunción ha sido la madre del actual propietario del documento que reseñamos, D. Gaspar Castellano de Gastón, que ha sido Presidente de la Diputación Provincial de Zaragoza (1979), Presidente de la Comunidad de Aragón (1982) y Parlamentario Foral de Navarra por Unión del Pueblo Navarro (1995-1999), al que agradecemos el habernos facilitado el documento, como parte de la Historia de la Medicina de Navarra.

\section{EL DOCUMENTO}

La primera inoculación de vacuna en el Valle de Baztán en el todavía Reino de Navarra se describe en los siguientes términos:

\footnotetext{
* Baztán. "Gran número de hijos de este Valle se han distinguido en las diferentes carreras del Estado. Rigiendo desde principio del siglo pasado -siglo XVIII- un Auto del Valle disponiendo erigir águilas en la fachada de su casa consistorial y en la nativa de cada uno a la memoria que hubiere alcanzado la dignidad de obispo, en la militar la de teniente general y en la magistratura a la de individuo de la Cámara de Castilla" Pascual Madoz ${ }^{2}$. En la actualidad el águila ha sido trasladada de la casa de Errazu a la de Irurita.
} 


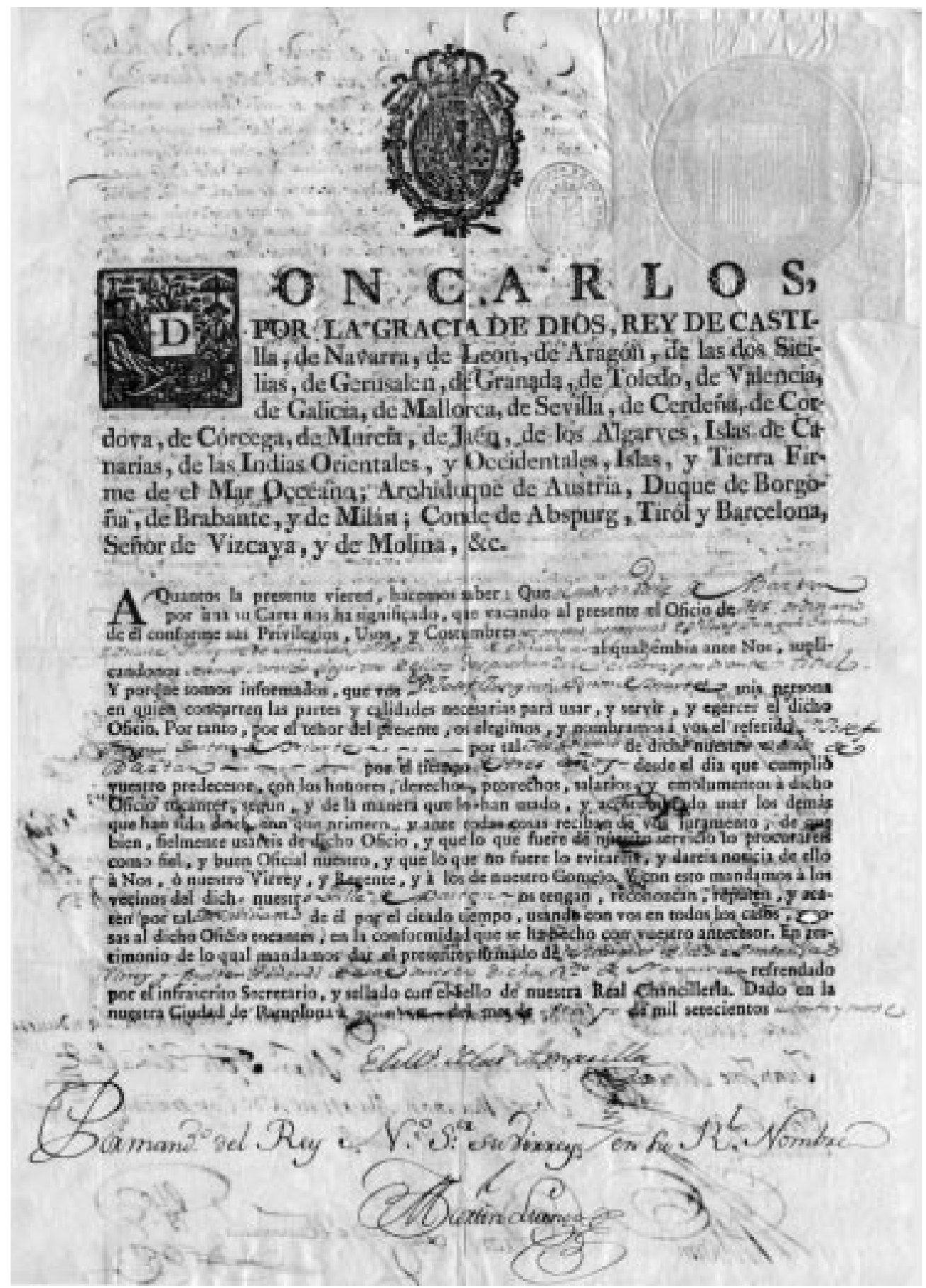

Figura 1. Nombramiento de D. Jose Joaquin Gaston de Iriarte, Alcalde juez capitán a guerra trienal del Noble Valle del Baztan el 22 de Mayo de 1799 (anverso). 


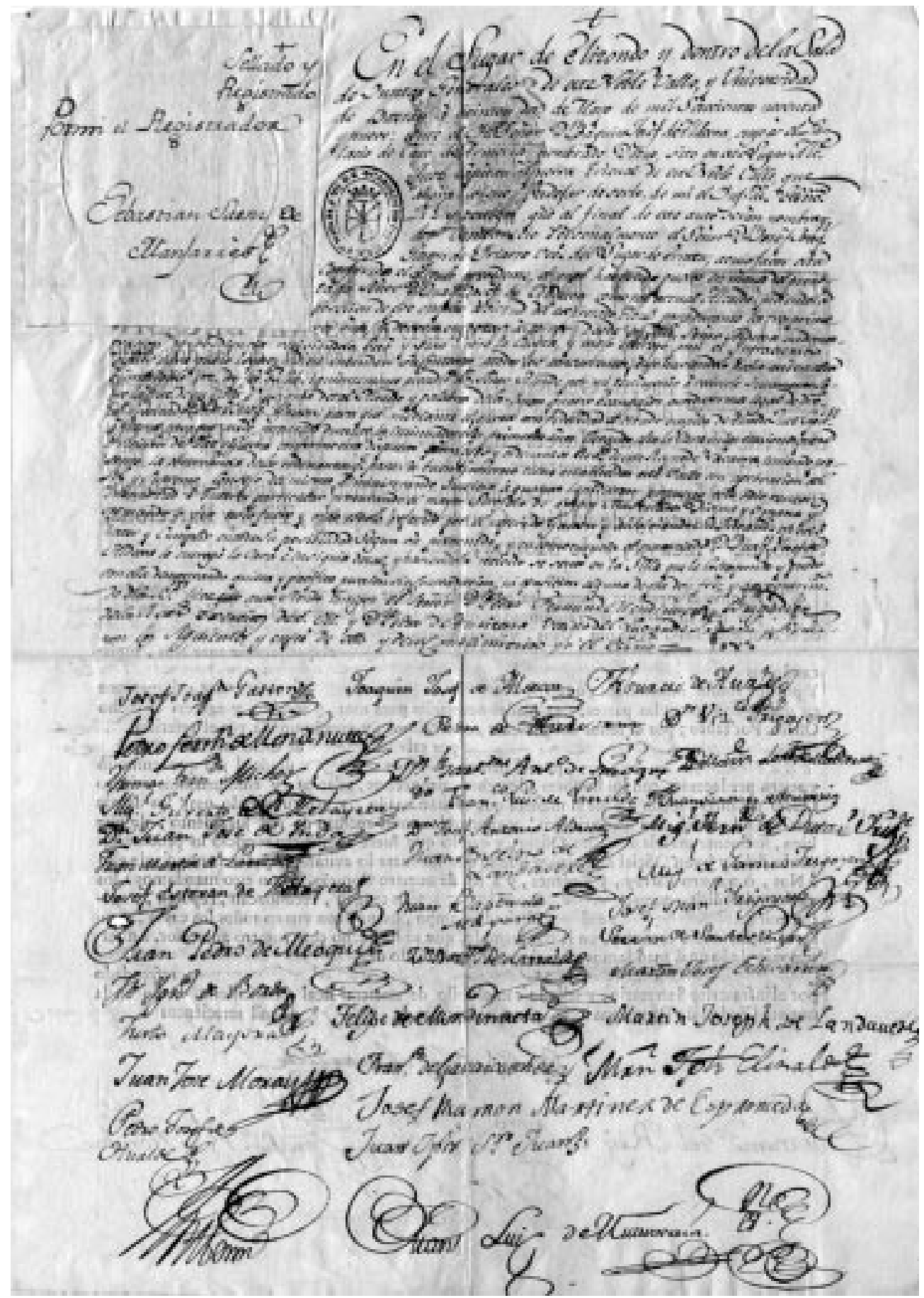

Figura 2. Nombramiento de D. Jose Joaquin Gaston de Iriarte, Alcalde juez capitán a guerra trienal del Noble Valle del Baztan el 22 de Mayo de 1799 (reverso). 

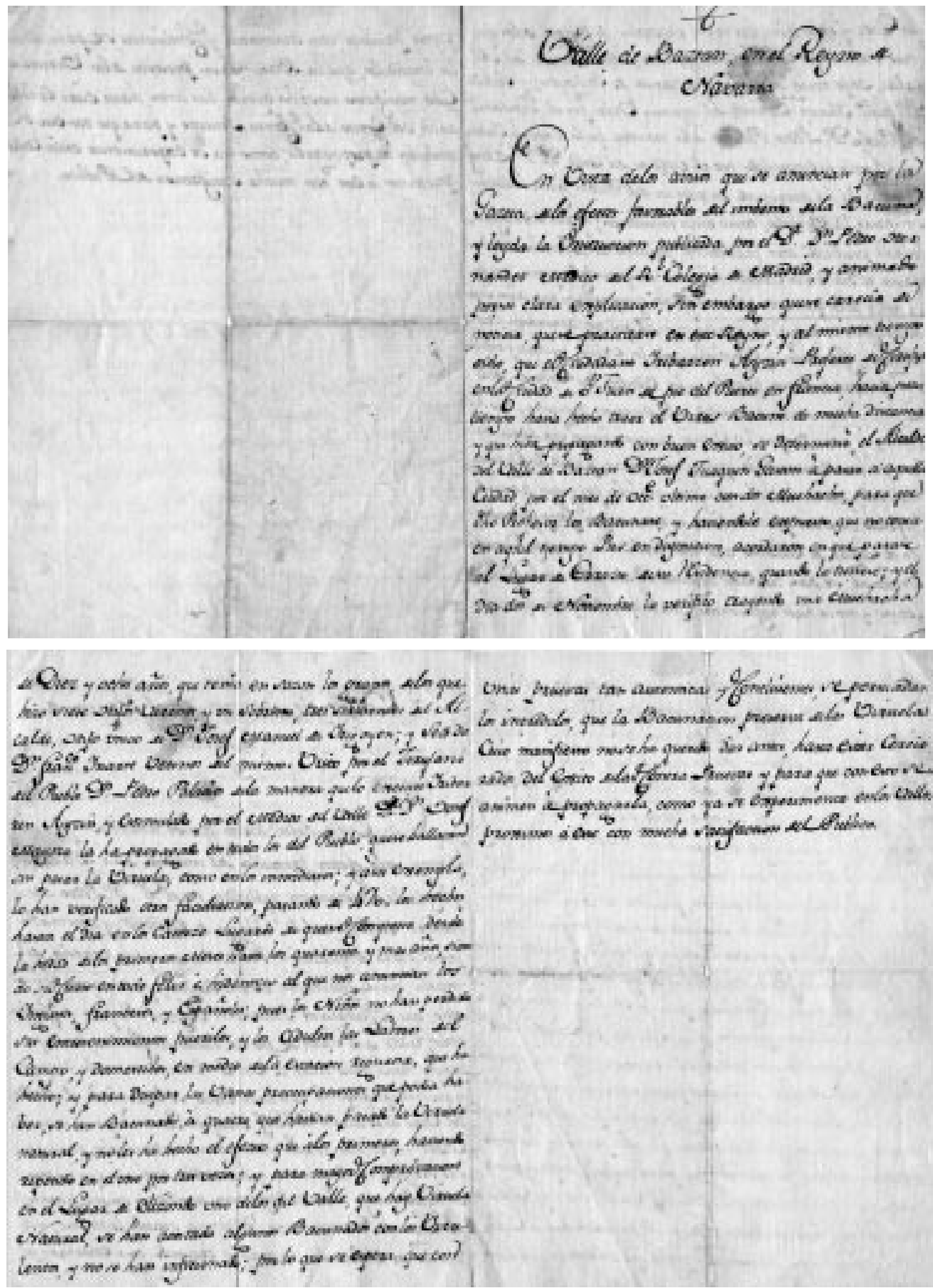

Figura 3. Documento que acredita la vacunación antivariólica el 2 de noviembre de 1801 en Errazu, valle del Baztan. 
Valle del Baztán en el Reyno de Navarra

En vista de los avisos que se anuncian por la Gazeta de los efectos favorables del invento de la Vacuna, y leída la Instrucción publicada por el Dr. Dn Pedro Hernández medico del Real Colegio de Madrid, y animado por su clara explicación, sin embargo que se carecía de noticia que se practicase en este Reino, y al mismo tiempo oído que el ciudadano Iribarren Ayzin Profesor de cirugía en la ciudad de San Juan de pie del Puerto en Francia hacia poco tiempo había hecho traer el virus vacuno de mucha distancia y que iba propagando con buen éxito, se determinó el Alcalde del Valle de Baztán Dn Josef Juaquin Gaston á pasar a aquella ciudad por el mes de Oct. $e^{e}$ último con dos muchachos, para que dicho Profesor los vacunase, y habiendole expuesto que no tenia en aquel tiempo pus en disposición, acordaron en que se pasase al Lugar de Errazu en su Residencia, cuando lo tuviere; y el día dos de Noviembre lo verificó trayendo una muchacha de diez y ocho años, que tenia en sazón los granos, de los que hizo siete hijos varones y un sobrino, tres sirvientes del Alcalde, hijo único de D. ${ }^{n}$ Josef Manuel de Irigoyen; y seis de D. ${ }^{n}$ Fran $^{C O}$. Iriarte vecino del mismo. Visto por el cirujano del Pueblo D. ${ }^{n}$ Pedro Palacios en la manera que lo ejecutó Iribarren Ayzin y estimulado por el medico del Valle Dr. D. ${ }^{n}$ Josef Mayora la ha propagado en todos los del Pueblo que se hallaban sin pasar la viruela, como en los inmediatos; y a su ejemplo lo han verificado otros facultativos, pasando de 470, los hechos hasta el día en los catorce Lugares en que se compone desde la edad de los primeros meses hasta los cuarenta y mas años siendo su curso en todo feliz e idéntico al que nos anuncian los Ingleses, Franceses y Españoles pues los niños no han perdido sus entretenimientos pueriles, y los adultos las labores del Campo y domésticos, en medio de la estación rigurosa, que ha hecho; y para disipar las vanas preocupaciones que podía haber, se han vacunado a cuatro que habían pasado la Viruela natural, y no les ha hecho el efecto que á los primeros, habiendo repetido en el uno por tres veces; y para mayor Comprobación en el lugar de Elizondo uno de los del Valle, que hay Viruela Natural, se han acostado algunos vacunados con los virulentos y no se han inficionado; por lo que se espera que con unas pruebas tan autenticas y Conclusiones, se persuadan los incrédulos, que la Vacunación preserva de las Viruelas; cuyo manifiesto no se ha querido dar antes hasta estar cerciorados del éxito de las contra pruebas y para que con esto se animen a propagarla, como ya se experimenta en los Valles próximos a este con mucha satisfacción de Publico.

\section{ANÁLISIS Y CONSIDERACIONES SOBRE EL DOCUMENTO}

El documento pone en evidencia que el estamento responsable político y sanitario en el valle de Baztán al inicio del siglo XIX estaba con información actualizada de los acontecimientos de Madrid y de Francia en el plano científico y al tanto del progreso de la época. La vacunación dada a conocer por Jenner en Londres en 1798, ya había sido introducida en Francia en 1799 y en España (Cataluña) el 3 de diciembre de $1800^{4}$. En Madrid ya se disponía de información del nuevo acontecimiento científico y se había practicado la vacunación con linfa procedente de París en los meses de abril-mayo de $1801^{5}$.

La propia Gazeta de Madrid el día 6 de enero de 1801 daba la noticia en los siguientes términos:

\section{Puigcerdá 16 de Diciembre.}

El Dr. D. Francisco Piguillem, socio de varios cuerpos literarios y Médico de esta villa, deseando verificar las calidades de la vacina, que ocupa en el día la atención de los Médicos más famosos de Francia é Inglaterra, se hizo traer de Paris una porción de virus ó materia vacínica, con la que inoculó 4 niños el día 3 del corriente. No obstante de haberse practicado esta inoculación en unos días los mas fríos y rigurosos, ha salido el grano, y ha seguido su curso con toda regularidad, sin que los niños vacinados hayan perdido ni un solo instante su alegría, ni padecido la menor molestia. Ayer, que era el día undécimo de la inoculación, vacinó el mismo profesor á otros 6 niños con la materia que sacó de los granos de los primeros. Esta operación se hizo en presencia del Gobernador, del Párroco y otros sugetos de distinción. La benignidad de la vacina, el curso tan regular que ha observado en los 4 primeros inoculados, y el haber sido enteramente conforme á la descripción que han dado los Médicos franceses é ingleses, hace esperar al Dr. Piguillem que esta invención podrá desterrar de aquí á algunos años las viruelas". 
Con fecha 8 de mayo la propia Gazeta de Madrid $^{6}$ anuncia la traducción del francés realizada por el Dr. Piguillem, del libro del Dr. Colon sobre la inoculación de la vacuna y su venta en Madrid, Barcelona, Valencia y Zaragoza y el envío "por carta"; y con ello difundía el descubrimiento y los efectos favorables de la "vacunación" frente a la "variolización".

Los médicos de la Corte se apresuraban a adherirse y divulgar a través de traducciones de textos, especialmente franceses, las instrucciones características y efectos beneficiosos de la vacunación. Uno de ellos, Pedro Hernández, médico del Real Colegio de Madrid publicó en mayo de 1801 " "Origen y descubrimiento de la Vaccinia" traduciendo del Francés "Decouverte de la vaccine et de la inoculation" de Francois Chaussier dando cuenta con ello del hallazgo de Edward Jenner*. Esta edición también fue publicitada por la Gazeta de Madrid Núm. 78, viernes 14 de agosto de 1801, pag. 868, en los términos que transcribo, que corresponde a la referencia que hace el Alcalde de Errazu que sin duda conoció y sobre la que tomó la decisión definitiva.

"Origen, descubrimiento y progresos de la vaccina: traducido del francés por el Dr. D. Pedro Hernández, Médico del Real colegio de esta corte, y de los Excmos Sres. Duques de Villahermosa y S. Cálos \&c. Esta obrita, que se halla adornada de estampas perfectamente grabadas alusivas al objeto, se divide en dos partes: la primera trata del origen, descubrimiento y progresos de la vaccina; y la segunda del modo de hacer la inoculación, de las calidades del fluido vaccino, y reglas que deben observarse durante la enfermedad, con un apéndice en que se resume lo substancial de la obra, con observaciones hechas en España, y señaladamente en Madrid, para la mayor inteligencia de los que practiquen la inoculación de la vaccina. Querer tratar aquí de la importancia y utilidad de este descubrimiento, mediante el cual se precaven los terribles estragos de las viruelas, seria una empresa tan dilatada como excusada: baste decir que sin embargo de los millares de niños de todas edades que se han inoculado hasta el día, ni uno ha fallecido por causa de esta inoculación, siendo al mismo tiempo tan fácil y sencilla, que los mismos padres, las madres, y aun las amas de cría, pueden executarla con toda felicidad sin auxilio de facultativo, y sin que para ello se necesite preparación ni cuidado particular. Véndese á 6 rs. Á la rústica en la librería de Castillo, frente á las gradas de S. Felipe”.

El Alcalde de Baztán fue conocedor "de los efectos favorables del invento de la Bacuna", "siendo en su curso en todo feliz e idéntico a que nos anuncian ingleses, franceses y españoles". El alcalde sabe también "que se carecía de noticia que se practicase en este Reyno" y además tenía información de que un médico de San Juan de Pie de Puerto, hacía poco tiempo había hecho traer el "Virus Bacuno" de mucha distancia, posiblemente de París, que iba propagando con buen éxito.

Estar al tanto de los asuntos de las localidades próximas de Francia ha sido y es intercambio habitual entre ambas zonas fronterizas, pero incluso en aquel siglo las relaciones de los valles pirenaicos navarros con la Baja Navarra (Francia) eran más frecuentes que con Pamplona Capital del Reino, por ser más fáciles y sobre todo más cortas aquellas comunicaciones, sin calzadas ni rodaduras; quizás por ello ignoraba que un mes antes ya se vacunaba en Pamplona.

El conocimiento de estos hechos por parte del Alcalde José Joaquín Gastón, está redactado minuciosamente en tercera persona: "se determinó el Alcalde del Valle

* Edward Jenner (1749-1823), hijo de un pastor protestante de Gloucestershire, que fue, en 1770, amigo y discípulo de John Hunter, prestándole una eficaz ayuda en sus experimentos. Había desde largo tiempo una tradición popular en Gloucestershire de que las muchachas de las lecherías que habían adquirido el cow-pox al ordeñar no padecían de las viruela, y observaciones similares se habían efectuado en Alemania y Francia. Enterado Jenner de este hecho por una lechera, pronto concibió la idea de ampliarlo en grande escala como profilaxia de la enfermedad. Al comunicar este proyecto a Hunter, éste le hizo su característica advertencia: "No lo pienses más; ensaya; ten paciencia y ten exactitud"; Volviendo a su casa, en Berkeley, comenzó a reunir sus observaciones en 1778 y el 14 de mayo de 1796 realizó la primera vacunación en un muchacho de la región, James Phipps, usando linfa del brazo de la lechera Sarah Nelmes, que había adquirido el cow-pox (vaccinia) del modo usual. El experimento fue llevado a la comprobación, supuesto que Phipps fue inoculado el 1 de julio con viruela, demostrándose la eficacia de la inmunización. (F.H. Garrison. Introducción a la Historia de la Medicina. Madrid: Calpe 1921 pág. 395-396). 
del Baztán” "a pasar a aquella ciudad". La sucesión concatenada de razones por las que se determinó el alcalde a pasar a San Juan de Pie de Puerto está descrita como un relato de decisión del alcalde, por lo que puede inferirse que su redactor es una tercera persona a la que el propio alcalde le da el encargo de escribirlo.

El alcalde se decide a buscar al médico vacunador francés y se desplaza con dos muchachos que pudieran ser dos hijos, a los que luego vacuna, cuyo es el objeto que le mueve al alcalde, pero como luego se ve que vacunó a tres criados, bien pudieran ser dos de ellos los que le acompañaron para traerse puesta la vacuna en el brazo. El intento fue vano porque el médico francés Dr. Iribarren no disponía de "Virus Bacuno" en ese momento y hubo de volverse de vacío no si antes contratar, se supone que ajustadas las costas, que el propio médico pasaría a Errazu a casa del alcalde con vacuna. Parece ser que el médico francés dispondría, de vez en cuando, de "cristales" en alguna ocasión "traída de mucha distancia", pero el Dr. Iribarren Ayzin sorprende al alcalde el día 2 de noviembre presentándose en su casa de Errazu con "virus bacuno" instalado en el brazo de una muchacha francesa por mas señas, de dieciocho años, al puro estilo jenneriano. Sin duda el Dr. Iribarren habría recibido virus vacuno posteriormente al viaje del Alcalde y mantendría series de muchachos y muchachas trasmitiendo la vacuna de brazo a brazo* Con una de ellas se decide a pasar a Errazu por difíciles caminos de herradura ${ }^{2}$ a través del escarpado paso fronterizo de la montaña de Izpegui en el invernal mes de Noviembre de 1801, más propicio para el contrabando, los exilios, los prófugos o la guerrilla que para el paso de la ciencia.

\section{LAS INOCULACIONES DE LA VACCINIA O VACUNA}

Del brazo de la muchacha "que tenia en sazón los granos" aprovechó a vacunar a sus siete hijos, a tres sirvientes; al hijo de un amigo, y otros seis de D. Francisco Iriar- te posible familiar del alcalde, ya que provendría de Casa Iriartea (Fig. 4).

El documento no está fechado pero puede deducirse con precision. El alcalde conocidas las informaciones desde Madrid que hemos precisado en el mes de mayo o más verosímil a partir de agosto de 1801 fecha de publicación de la instrucción del Dr. Pedro Hernández, decide ir a buscar la vacuna en el mes de octubre donde sabe que existe en Francia; y fallido el viaje, al siguiente mes de noviembre, se producen las inoculaciones en 18 vecinos de Errazu. Josef Juaquín Gastón dejó de ser alcalde en el mes de mayo del siguiente año 1802 , por lo que la fecha se precisa el 2 de noviembre de 1801; once meses después de la primera vacunación en España (3 de diciembre de 1800) que Francisco Piguillem realizó en Puigcerdá en diciembre de 1800 con vacuna (linfa colocada en cristales) traída desde París. Pocos meses después se inició la vacunación en Madrid en abril y mayo de 1801, por los doctores Ignacio de Jáuregui e Ignacio María Ruiz de Luzuriaga ${ }^{4}$ respectivamente, con linfa recibida también desde París. La introducción de linfa vacunal directamente del brazo en Navarra resulta singular y eficacísima ya que inoculó el primer día con virus vacuno activo a 18 personas que a su vez fueron fuente de difusión posterior. El octavo día de la inoculación era el más propicio para difundir la vacuna.

Esta circunstancia tuvo un efecto positivo añadido: el cirujano del pueblo D. Pedro Palacios vio y aprendió la técnica del médico vacunador francés y con las nuevas pústulas estuvo en condiciones de iniciar la primera "campaña" de vacunación en Navarra en la manera que lo "executó Iribarren Ayzin" y a su vez enseñar en cadena a otros sin duda también cirujanos. La inoculación era una "facultad" de los cirujanos -sangradores, oficio de arte menor, con autorización para sangrar cauterizar y otras técnicas cruentas que aprendían de oficio, y en caso del aprendizaje académico, lo hacían en romance, estando prohibido a los médicos "latinos"

* El Dr. Iribarren que debía de ser muy conocido es citado como Iribarraiten por J. Ramos ${ }^{10}$ como vacunador en San Juan de pie de Puerto. 
el intervenir con instrumentos sobre el cuerpo. Es por ello que en ese año que nos ocupamos intervino "el Cirujano del Pueblo" lo que indica que los pueblos necesitaban más al cirujano romancista que al médico versado en "latines", que en este caso lo era para todo el Valle el Doctor Don Josef Mayora.

\section{CAMPAÑA DE VACUNACIÓN COLECTIVA}

Toma el relevo en la difusión de la vacunación Pedro Palacios "estimulado" por el médico del valle que desarrolla la primera vacunación colectiva que se conoce hasta la fecha, vacunando primero a los habitantes de Errazu y después a los de los 14 lugares o pueblos del Valle que en la época contaba con 7.300 habitantes ${ }^{2}$, ayudado por otros facultativos compañeros posiblemente cirujanos alcanzando la vacuna a todas las edades "desde la edad de los primeros meses hasta los cuarenta y más años". El documento expresa que, al día de la fecha en la que se redacta el mismo, se habían vacunado 470 personas.

Cuál sea la fecha de la redacción del documento no se puede precisar pero lo sería en los meses del invierno de 18011802 "en la estación rigurosa que ha hecho", y había pasado tiempo suficiente desde el dos de noviembre para inmunizar brazo a brazo hasta 470 personas. Como se ve de un sólo brazo (la muchacha de San Juan de Pie del Puerto) consiguieron 18 vacunados. En todo caso fue redactado con tiempo suficiente como para conocer el efecto vacunal con la "contraprueba".

En el inicio del siglo XVIII, la medicina, y en este caso la cirugía está iniciando un desarrollo dentro del pensamiento del empirismo lógico ${ }^{8}$ en el que la experiencia individual debe someterse al razonamiento lógico de lo percibido por los sentidos; no estan desarrolladas las bases probabilísticas de la causa-efecto y cada médico debe observar y comprobar por sí mismo cómo lo hiciera Edward Jenner en la pri-

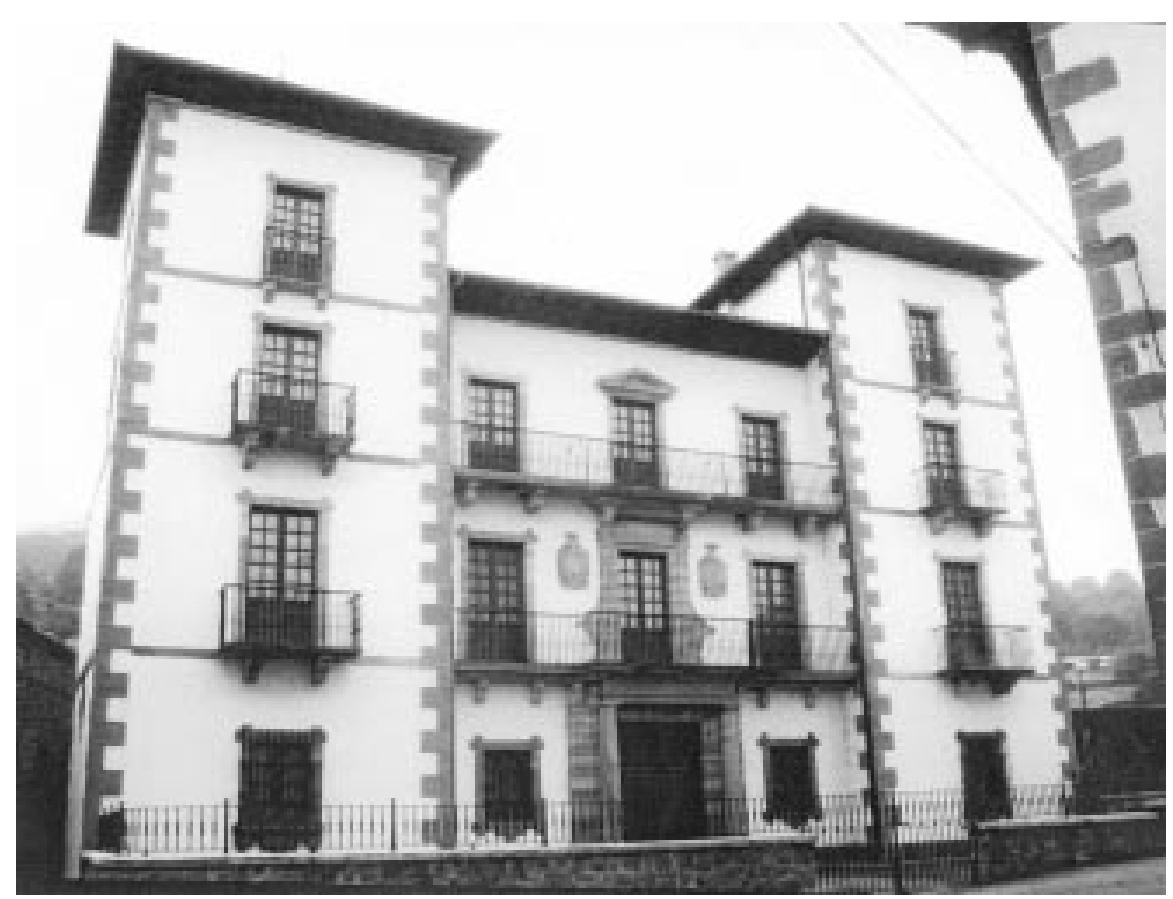

Figura 4. Casa Iriartea (Siglo XVIII) de la familia Gastón de Iriarte en Errazu. En ella se realizaron las vacunaciones antivariolicas el 2 de noviembre de 1801 por el médico francés de San Juan de Pie de Puerto, Dr. Iribarren Ayzin. 
mera vacunación. Nuestros sanitarios vacunadores del Baztán realizan una doble contraprueba: Inocular "virus Bacuno" en personas que ya habían padecido y curado de la viruela humana natural, viendo que la vacuna "no les ha hecho efecto"; y una segunda contraprueba heroica acostando a vacunados con enfermos de viruela " $y$ no se han inficionado". La protección era absoluta pues no contraen la enfermedad. Éxito rotundo y comprobado.

\section{EL OBJETO DEL DOCUMENTO}

La finalidad con la que se describe todo el hecho novedoso de la vacunación en el Valle del Baztán no es otro que el de comunicar el éxito del nuevo recurso de la medicina; "Cuyo manifiesto no se ha querido dar antes hasta estar cerciorados del éxito de las contra pruebas"; para que se propague la vacunación y para aportar pruebas fehacientes de la eficacia y de la seguridad y comodidad. Es por ello que bien puede asegurarse, que la redacción se realiza por interés científico y filantrópico, y que el plural utilizado "estar cerciorados" pone al descubierto que son varias las personas implicadas en el proceso y posiblemente fueron los sanitarios que han participado en la vacunación y en los ensayos de la contraprueba, los que redactan el documento.

El documento quedó archivado en la casa Iriartea del Alcalde en Errazu y luego en el Palacio de la familia Gastón de Iriarte en Irurita de donde le damos la luz.

\section{LA VACUNACIÓN JENNERIANA EN EL RESTO DE NAVARRA}

En el año 1802 la vacunación era una práctica extendida en Navarra tal como lo da a conocer el cirujano de Puente la Reina Diego de Bances en su "Tratado de Vaccinia o Viruela Vacuna" promotor y distribuidor de linfa vacunal a varios pueblos, dando a conocer que en esa fecha ya se estaba vacunando en el Valle del Baztán, en Pamplona en Tudela y en Obanos ${ }^{9}$.

El inicio de la vacunación en Pamplona puede comprobarse que se efectuó dos meses antes que en Baztán, en septiembre de 1801, lo que no era conocido por nuestro Alcalde Gastón de Errazu: "que se carecía de noticia que se practicase en este Reyno". La Junta del Hospital Civil autoriza en efecto a sus médicos iniciar la práctica de la "vaccinación" el 27 de agosto de 1801 , lo que llevan a cabo en septiembre y las contrapruebas en febrero de $1802^{10}$.

Los Profesores en Medicina y Cirugía del Hospital General de Pamplona, D. Martín de Apezarena, Vicente Martínez, D. Lorenzo Mariartegui, y Matheo López solicitan autorización para que les "entreguen" niños expósitos para "principar" la nueva técnica de la "vaccinación". El documento no tiene fecha. La Junta del Hospital da autorización sobre la misma hoja de la solicitud con fecha 27 de agosto (Fig. 5). Puede señalarse que dos de ellos tienen tratamiento de DON y los otros dos no; por lo que distinguimos a los médicos de los cirujanos. Solicitud y respuesta se producen en los términos siguientes ${ }^{11}$ :

$+$

M.Y.S.

Los Profesores de Medicina y Cirujía del Hospital Grâl con el respeto debido hacen presente q. ${ }^{e}$ después de repetidas consultas celebradas en el mismo Hospital y presididas $p^{r}$. el $S^{r}$ Arcediano de la Tabla, Yndividuo Protector de la Junta han proferido unanim. te su dictamen relativo a la vaccinacion, $q^{e}$ substancialm. te se reduce a $q .{ }^{e}$ no solo esutil y ventajosa esta inocullac. ${ }^{n}$ inglesa, sino necesaria e indispensable p. ${ }^{a}$ preservar la espécie humana del cruel azote de la viruelas naturales, y q.e la Junta no solo puede, si no que debe sujetar los niños expósitos à esta inocente operación.

En esta atención á V.S. sup. can se sirva entregarselos à su dirección para elegir entre ellos los más apropósito p. ${ }^{a}$ principiar desde luego à poner en practica el saludable medio, generalizado ya en Inglaterra, Suiza, Alemania, Francia, Ginebra y Madrid, fabor q. esperan en obsequio de la humanidad.

(Fdo) $D^{n}$ Martin de Apezarena, Vizente Martínez, D. ${ }^{n}$ Lo. $^{o}$ Mariartegui, Matheo Lope $z^{11}$.

Pamplona 27 de agosto de 1801 
Habiendo tenido repetidas sesiones, y precedido el serio detenido conocim. to que exige este asunto de este memorial enq. ${ }^{e}$ diversas conferencias ha oído a los exponente el $S^{r}$ Arcediano de Tabla con Comisión de la Junta, Resultando con entera uniformidad p. ${ }^{r}$ las noticias adquiridas, ser de manifiesto beneficio álos Niños lo que se solicita y teniendo pnte. las Soveranas intenciones y $R{ }^{S}$ Ordenes ácerca de los Hospitales y Expósitos se da Comisión particular al $S^{\text {or }} D^{n}$ Pedro Ant. ${ }^{o}$ Aranegui para que atendiendo Spre al bien de los Expósitos y à llenar lo que debe la Junta p. ${ }^{r}$ su Instituto pueda determinar y disponer lo que se solicita, con los que á presencia delas circunstancias lo estimase álos mismos Niños util y se le confiere facultad para Resolber quanto fuere necesario, àfin deque se hagan los esperim ${ }^{\text {tos }}$ en el mejor modo posible, procedien-

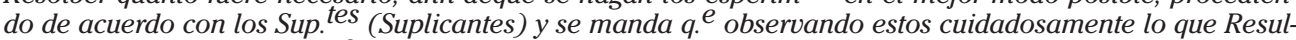
tase en todos los casos enq. ${ }^{e}$ se prueve, informen deello con especificación àla Junta para los efectos convenientes (Rubricado). Con Acuerdo de la Junta. Josef Antonio de Goñi (Secretario).

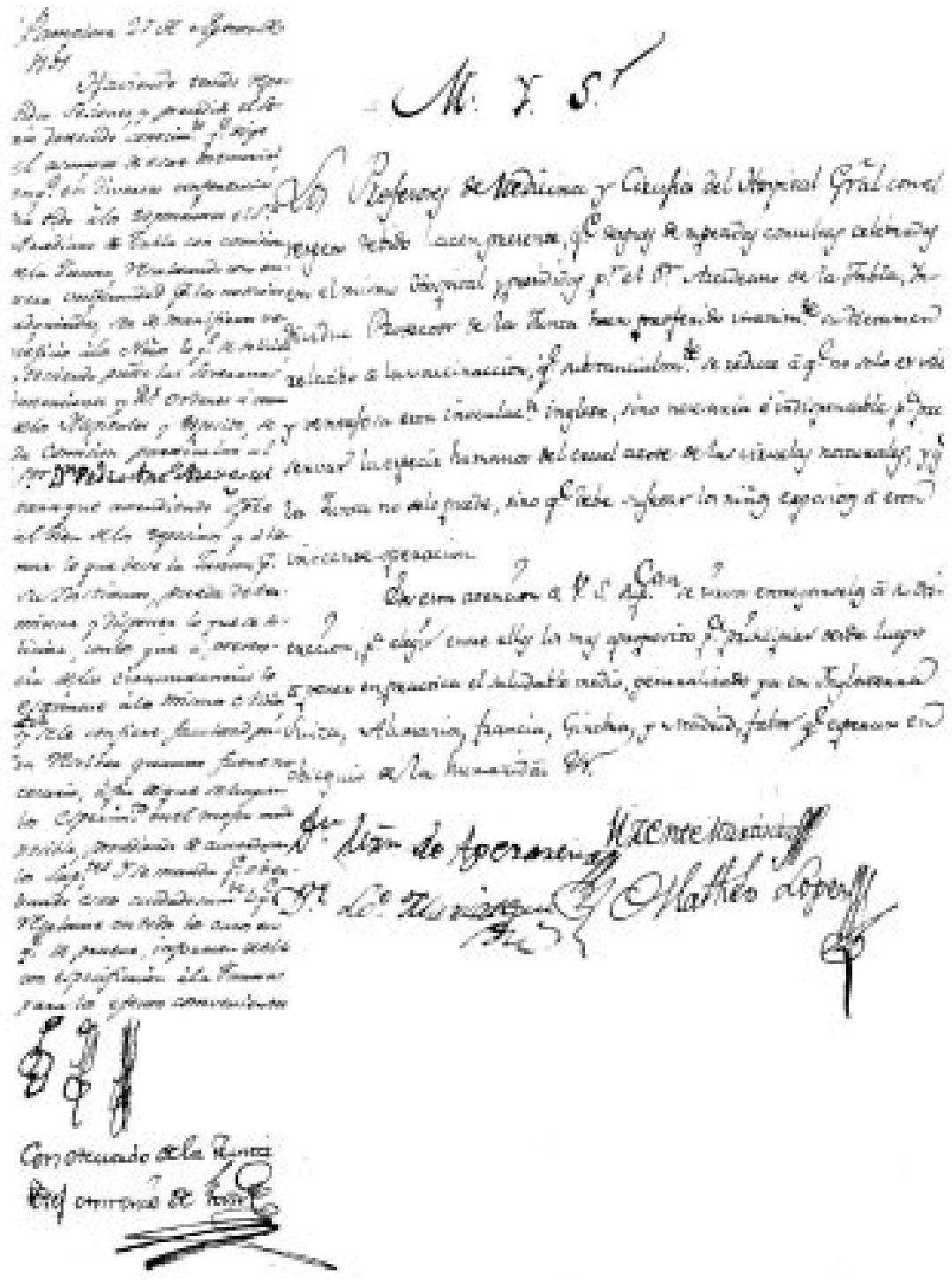

Figura 5. Solicitud y autorización a los médicos y cirujanos del Hospital General de Pamplona para vacunar a los niños expósitos del mismo: agosto de 1801. 
Los mismos médicos y cirujanos promovieron esta técnica posteriormente con los niños expósitos de la inclusa por toda la provincia, práctica de las inoculaciones, que se ofertaba a toda la población ${ }^{10}$. No encontramos referencia del origen de la linfa vacunal utilizada en la primera y sucesivas vacunaciones en Pamplona, pero sería lógico pensar fueran "cristales" procedentes de Madrid.

El Ayuntamiento, con fecha 2 de diciembre de 1801 solicita información de los Ayuntamiento de Soria y San Juan de Pie de Puerto sobre los efectos de la vacunación, siendo las respuestas favorables ${ }^{10}$. El Ayuntamiento en esa fecha conocería las vacunaciones realizadas en el Hospital, pero al parecer era escéptico ya que no se habían hecho todavía contra-pruebas. Estas se llevan a cabo el 12 de mayo de 1802 en 4 niños expósitos vacunados. Se llevaron a cabo en los niños: Ciriaco, de 5 años vacunado el 3 de noviembre de 1801; Luis, de 3 años y 10 meses vacunado en septiembre de dicho año; Petra, de 5 años vacunada a la vez que Luis; y Fermina de 5 años vacunada en diciembre del mismo $a_{n}{ }^{10}$. Se les sometió a inoculaciones de pústulas de un soldado con viruela en el ambiente varioloso del Hospital Militar.

La introducción de la vacunación fue por tanto bastante temprana en Navarra, en septiembre de 1801 en Pamplona ${ }^{11}$ y en Noviembre en el Valle de Baztán, pero sin embargo las dificultades técnicas del mantenimiento de los bancos públicos o privados de vacuna, dificultaron su aplicación a lo largo de todo el siglo XIX y no era de práctica habitual, pues lo brotes continuos obligaba a finales de este siglo a continuos llamamientos del Gobierno de la Nación* y de la Junta Provincial de Sanidad a los Alcaldes, médicos titulares y población recomendando insistentemente la vacunación en general y las revacunaciones ${ }^{12}$, aunque la obligatoriedad de la vacunación y revacunación antivariólica ha de esperar al siglo siguiente por Real Decreto de 15 de Enero de $1903^{13}$ cuando la vacuna ya se produce en la piel de terneras.

\section{A MODO DE CONCLUSIÓN Y EN RECUERDO DE FRANCISCO XAVIER BALMIS}

El documento inédito de la vacunación en el Valle de Baztán que tenemos la fortuna de dar a conocer nos permite saber que el ejercicio de la medicina en el medio rural en Navarra estaba al tanto de los conocimientos y desarrollo de otros países europeos al iniciar al siglo XIX, siglo convulso en el que se perdieron después las oportunidades de incorporación al desarrollo y progreso europeo, y con ello el prestigio y reconocimiento, por el resto de países ${ }^{\wedge}$. En este largo olvido e incuria, ha caído por muchos años uno de los hechos más sobresalientes de la Sanidad Internacional llevada cabo por la Corona Española entre 1803 y 1806 por mandato y financiación de Carlos IV; la expedición para la difusión de la vacunación antivariólica dando la vuelta al mundo bajo la dirección del doctor alicantino Francisco Xavier Balmis, ayudado por el Dr. Salvany a bordo del velero María Pita llevando niños de la inclusa de La Coruña que fueron progresivamente vacunados brazo a brazo para mantener activo el "Virus vacuno" a lo largo de la travesía a Canarias, a América y a Filipinas sucesivamente ${ }^{14}$. Si Edward Jenner es el precursor de la prevención de las enfermedades infecciosas Francisco Xavier Balmis y la Corona española son los precursores de la Sanidad Internacional que si bien se inició en la lucha contra la viruela en Diciembre de 1803, finalizo con éxito con la declaración por la Organización Mundial de la Salud en la Asamblea de 1977 la erradicación de la enfermedad.

* El Gobierno dio insistentes recomendaciones de vacunación antivariólica: Ley Orgánica General de Sanidad 1855; circular de 17 de enero de 1880; R.D. de 18 de agosto de 1891. J. Abella. Tratado de Sanidad. El Consultor de los Ayuntamientos y de los Juzgados Municipales. Madrid, 1914.

$\wedge$ "Hay dos palabras para resumir la historia de este siglo en sus etapas más significativas y también, por desgracia, en su conjunto: una es cambio; otra caos." (pag. 585) "La implantación del reaccionarismo en España se facilitó al amparo de la reacción general europea, cuyo escenario fue el Congreso de Viena en 1815 donde a España, vencedora con Rusia del enemigo común, no se le concedió rango de gran potencia" (pag 606) Ricardo de la Cierva. Historia Total de España .Madrid: Editorial Fénix, 1997. 
La expedición de Balmis ha sido sistemáticamente olvidada por toda la comunidad internacional y en particular por los historiadores extranjeros. Una de las fuentes anglosajonas más acreditadas de inicio del siglo XX es sin duda Fielding Garrison; que en su "Historia de la Medicina" 15 es preciso con la medicina inglesa, americana, alemana o francesa, y en su relato sobre Edward Jenner, cuando cita a los pioneros de la vacunación en Europa, hace referencia a tantos médicos que practicaron y difundieron la vacunación en el mundo civilizado, pero ignora la existencia del hito de la expedición mundial de Balmis. Tampoco hoy es mucho más recordado entre los científicos e historiadores de la sanidad española, a pesar de encontrarnos en el 200 aniversario de la heroica hazaña sanitaria, de la primera campaña mundial de la vacunación antivariólica.

Las buenas intenciones del Gobierno creando una Comisión Interministerial para la conmemoración del acontecimiento, cuyos buenos deseos no se han materializado, si bien esfuerzos unilaterales como conferencias en círculos limitados: Academia Nacional de Medicina, Instituto de Salud Carlos III; o manifestaciones localistas por parte de los ayuntamientos (Exposición conmemorativa en La Coruña: Noviembre 2003-2004); ó ediciones de libros: "En nombre del niño. La Real Expedición filantrópica de la vacuna (18031806)" de Emilio Balaguer Perigüel y Rosa Ballester Añon. Sociedad Española de Pediatria; Monografía no 2, 2002; "Balmis et Variola”. Jose Tuells y Susana Ramírez. Generalitat Valenciana,2003; o "El sueño ilustrado", de Juan Carlos Herrera Hermosilla. Ediciones Paracelso, 2004, han conseguido que el centenario no fuera silenciado.

\section{BIBLIOGRAFÍA}

1. MartinenA J.J. Navarra Castillos y Palacios. Pamplona: Caja de Ahorros de Navarra, 1980.

2. MADOZ P. Diccionario Geográfico-estadísticohistórico de España, Tomo IV. Madrid, 1941 (Reproducción Facsimil Biblioteca Santa Ana. Almendralejo, 1990).

3. García-SAnZ Marcotegui A. Diccionario Biográfico de los Diputados Forales de Navarra (1840-1931). Pamplona: Gobierno de Navarra 1996.

4. Olagüe de Ros G, Astrain Gallart M. Propaganda y Filantropismo: los primeros textos sobre la vacunación jenneriana en España (1799-1801) Medicina e Historia 1995, 56: IXVI.

5. Gazeta de Madrid núm 2, 6/ 01/ 1801: 20.

6. Gazeta de Madrid núm 37, 8/ 05/ 1801: 460.

6. Gazeta de Madrid núm 78, 14/ 08/ 1801: 868.

7. Lain Entralgo P. Historia de la Medicina. Madrid: Salvat Editories, S.A. 1978 (2 ${ }^{\underline{a}}$ reimpresión).

8. Gil Sotres P. La Real Expedición Filatrópica de la Vacuna: 200 años de un hito de la Medicina Preventiva. Pamplona: Diario de Navarra 2003, 30 Noviembre: 89.

9. Ramos Martínez J. La Salud Pública y el Hospital General de la Ciudad de Pamplona en el Antiguo Régimen (1700-1815). Pamplona: Gobierno de Navarra, serie Historia 60, 1989.

10. Archivo General de Navarra, Hospital, Título 11, número 36.

11. Junta Provincial de Sanidad 1870-1903. Departamento de Salud. Gobierno de Navarra. Biblioteca (Manuscrito).

12. Real Decreto de 15 de Enero de 1903 sobre medidas Preventivas contra la viruela. Tratado de Sanidad. Madrid: El Consultor de los Ayuntamientos y de los Juzgados Municipales 1914: 440-447.

13. NAVARRo R. Historia de la Sanidad en España. Barcelona: Lunwerg editores, 2002: 97-99.

14. GARRISON F.H. Introducción a la Historia de la Medicina. Madrid: Calpe, 1921: 399. 